\title{
A Study on Effects of Leaking Carbon Dioxide Gas on Surgeons during Laparoscopic Surgeries
}

\author{
Mallikarjuna Manangi ${ }^{1}$, Ranjitha Gangadharaiah², Santhosh S Chikkanayakanahalli ${ }^{3}$, Madhuri G Naik ${ }^{4}$, Arun Balagatte Jayappa ${ }^{5}$
}

\begin{abstract}
Background: Laparoscopic surgery is gold standard for treating various abdominal diseases. Carbon dioxide, having high safety profile, is the most commonly used gas for insufflating peritoneal cavity for accurate visualization and operative manipulation. Despite the fact that $\mathrm{CO}_{2}$ is naturally present in the atmosphere, i.e., $0.035 \%$ (350 ppm), it is one of the most overlooked toxic gases. $\mathrm{CO}_{2}$ breathing causes numerous cardiorespiratory responses and psychological reactions, such as impaired vision, diminished motor control, slowed responses, disorientation, or reduced attentional capacities that may jeopardize a worker's health and safety. At high concentrations (8\%), it has been shown to cause unconsciousness almost instantaneously and respiratory arrest within 1 minute. As laparoscopic surgeons are under constant exposure of leaking $\mathrm{CO}_{2}$ gas, this study is taken up to evaluate the effects of $\mathrm{CO}_{2}$ on them by a noninvasive technique that measures end-tidal $\mathrm{CO}_{2}$ of operating surgeons at the beginning and end of laparoscopic surgeries.

Objective: To evaluate the effects of leaking $\mathrm{CO}_{2}$ gas on surgeons during laparoscopic surgeries.

Methods: A Mini-Mental State Exam (MMSE) score and $\mathrm{EtCO}_{2}$ levels (using a capnometer with $4 \mathrm{~L}$ of oxygen/minute) of operating surgeons were obtained before the start of surgery. After surgery, $\mathrm{MMSE}$ scores and $\mathrm{EtCO}_{2}$ levels were again documented, compared, and analyzed using SPSS software.

Results: The mean $\mathrm{EtCO}_{2}$ before surgery was found to be 30.86 with standard deviation of 4.03 and that after surgery was 31.23 with standard deviation of 3.85 with mean duration of surgery being 73 minutes. Correlation of individual $\mathrm{EtCO}_{2}$ values before and after surgery did not show significant changes ( $p$ value $=0.534$ ). The difference in MMSE scale scores before and after surgery for all participated surgeons was insignificant. Conclusion: In healthy surgeons performing laparoscopic surgeries, there are no effects following exposure to leaking carbon dioxide.

Keywords: Air quality, Carbon dioxide, $\mathrm{CO}_{2}$, EtCO $\mathrm{CO}_{2}$, Laparoscopic surgeries, Laparoscopy, Leaking $\mathrm{CO}_{2}$.

World Journal of Laparoscopic Surgery (2021): 10.5005/jp-journals-10033-1446
\end{abstract}

\section{INTRODUCTION}

Laparoscopic surgery has established itself as a gold standard for treating various abdominal diseases in the recent decades, with benefits including but not limited to improved cosmesis, reduced surgical trauma and postoperative pain, and expedited patient recovery times. ${ }^{1}$ Carbon dioxide $\left(\mathrm{CO}_{2}\right)$, because of its high safety profile, is the most commonly used gas for insufflating the peritoneal cavity for accurate visualization and operative manipulation. Despite the fact that $\mathrm{CO}_{2}$ is naturally present in the atmosphere, i.e., $0.035 \%$ (350 ppm) and we exhale it while breathing, $\mathrm{CO}_{2}$ is one of the most overlooked toxic gases. $\mathrm{CO}_{2}$ is heavier than air with a density of 1.5 times that of fresh air. When it is released into an enclosed space, it tends to settle to the bottom, reaching the highest concentration in the lowest parts of space. Carbon dioxide breathing causes numerous cardiorespiratory responses, but there appear to be no disabling physiological effects or clinical symptoms associated with breathing up to $5 \% \mathrm{CO}_{2} \cdot{ }^{2-4}$ Nonetheless, there still may be psychological reactions, such as impaired vision, diminished motor control, slowed reactions and responses, disorientation, or reduced attentional capacities that may jeopardize a worker's health and safety. ${ }^{5,6}$ The physiological effects of carbon dioxide on the central nervous system have been roughly classified. They are both direct and indirect in their mechanism of stimulation.

- Direct stimulation of the respiratory centers in the medulla and spinal cord.

- Stimulation of the special nerve endings (chemoreceptors) in the carotid bodies and aortic arch, with the resultant vasodilator action on the cerebral blood vessels.
1,3,4 Department of General Surgery, Bangalore Medical College and Research Institute, Bengaluru, Karnataka, India

${ }^{2}$ Department of Anaesthesiology, Bangalore Medical College and Research Institute, Bengaluru, Karnataka, India

${ }^{5}$ Department of Pulmonology, Bangalore Medical College and Research Institute, Bengaluru, Karnataka, India

Corresponding Author: Madhuri G Naik, Department of General Surgery, Bangalore Medical College and Research Institute, Bengaluru, Karnataka, India, Phone: +91 08123639816, e-mail: naikmadhurig@gmail.com

How to cite this article: Manangi M, Gangadharaiah R, Chikkanayakanahalli SS, et al. A Study on Effects of Leaking Carbon Dioxide Gas on Surgeons during Laparoscopic Surgeries. World J Lap Surg 2021;14(2):103-105.

Source of support: Nil

Conflict of interest: None

- Direct stimulation of the vasomotor centers in the hypothalamus, midbrain, and medulla.

- Direct action on the cerebral blood vessels.

- Effect on the affinity of blood for oxygen. ${ }^{7}$

The most important control of cerebral blood flow is chemical. The cerebral vascular bed is extremely sensitive to changes in arterial $\mathrm{CO}_{2}$ tension and also to a lesser extent to decrease in $\mathrm{O}_{2}$ tension. ${ }^{8}$

US Occupational Safety and Health Administration (OSHA) has established a permissible exposure limit (PEL) for carbon dioxide of 5000 ppm (0.5\%) averaged over an 8-hour workday.

(c) Jaypee Brothers Medical Publishers. 2021 Open Access This article is distributed under the terms of the Creative Commons Attribution 4.0 International License (https://creativecommons.org/licenses/by-nc/4.0/), which permits unrestricted use, distribution, and non-commercial reproduction in any medium, provided you give appropriate credit to the original author(s) and the source, provide a link to the Creative Commons license, and indicate if changes were made. The Creative Commons Public Domain Dedication waiver (http://creativecommons.org/publicdomain/zero/1.0/) applies to the data made available in this article, unless otherwise stated. 


\section{Symptoms of Different Levels of Carbon Dioxide Exposure}

- 10000 ppm (1.0\%): Typically no effects, possible drowsiness.

- 15000 ppm (1.5\%): Mild respiratory stimulation for some people.

- 30000 ppm (3.0\%): Moderate respiratory stimulation, increased heart rate, and blood pressure.

- 50000 ppm (5.0\%): Strong respiratory stimulation, dizziness, confusion, headache, and shortness of breath.

- 80000 ppm (8\%): Dimmed sight, sweating, tremor, unconsciousness, and possible death. ${ }^{9}$

Since the likelihood of laparoscopic surgeons getting exposed to $\mathrm{CO}_{2}$ gas due to leaky or faulty instruments or even during normal circumstances cannot be ruled out, this study is taken up to evaluate the effects of leaking $\mathrm{CO}_{2}$ on them.

End-tidal $\mathrm{CO}_{2}\left(\mathrm{EtCO}_{2}\right)$ monitoring is a noninvasive technique that measures the partial pressure or maximal concentration of carbon dioxide at the end of an exhaled breath, which is expressed as a percentage of $\mathrm{CO}_{2}$ or $\mathrm{mm} \mathrm{Hg}$. The normal values are 5 to $6 \%$ $\mathrm{CO}_{2}$ in exhaled breath, which is equivalent to 35 to $45 \mathrm{~mm} \mathrm{Hg}$. When $\mathrm{CO}_{2}$ diffuses out of the lungs into the exhaled air, a device called capnometer measures the partial pressure or maximal concentration of $\mathrm{CO}_{2}$ at the end of exhalation.

Capnometry is a measurement of end-tidal $\mathrm{CO}_{2}$ partial pressure $\left(\mathrm{PEtCO}_{2}\right) \cdot \mathrm{PEtCO}$ closely approximates $\mathrm{PaCO}_{2}$ at the end of normal expiration in conditions with normal perfusion and ventilation and therefore makes the difference between $\mathrm{PaCO}_{2}$ and $\mathrm{PEtCO}_{2}$ minimal. In healthy individuals, there is essentially no alveolar dead space, which represents the volume of gases in non-perfused alveoli. This means that $\mathrm{PEtCO}_{2}$ equals $\mathrm{PaCO}_{2}$, and with correct sampling, $\mathrm{P}(\mathrm{a}-\mathrm{a}) \mathrm{CO}_{2}$ difference equals $\mathrm{P}(\mathrm{a}-\mathrm{et})$ $\mathrm{CO}_{2}$ difference, which makes $\mathrm{PEtCO}_{2}$ a good estimate of $\mathrm{PaCO}_{2}{ }^{10}$

\section{Objective of the Study}

To evaluate the effects of leaking $\mathrm{CO}_{2}$ gas on surgeons during laparoscopic surgeries.

\section{Materials and Methods}

Type of the study: Prospective cohort study

Time period: August 2018 to September 2018

Sample size: Based on pilot study, the difference in $\mathrm{EtCO}_{2}$ was about 3 to $4 \mathrm{~mm} \mathrm{Hg}$.

Assuming a $10 \%$ difference in $\mathrm{EtCO}_{2}$ before and after surgery with a power of $80 \%$ and alpha error of 0.05 , a sample size of 10 was required. For further validation of the study and assuming a dropout rate of $10 \%$, a total sample size of 20 was taken.

\section{Inclusion Criteria}

- Surgeons and surgical residents willing to give written informed consent.

- Surgeons and surgical residents of either sex aged 25 to 65 years.

- Surgeons and surgical residents performing laparoscopic procedures for more than 1 hour.

\section{Exclusion Criteria}

- Not willing to participate in the study.

- Age $<25$ years and age $>65$ years.

- Preexisting pulmonary conditions.

- Pregnancy.
- Surgeries spanning less than 1 hour.

- Chronic smokers.

- Hematological disorders.

Source of data: Clinical data are collected from the surgeons performing laparoscopic procedures in Victoria hospitals from August 2018 to September 2018.

\section{Methodology}

Ten surgeons performing laparoscopic surgeries for more than 1 hour in departments of general surgery in Victoria hospitals from August 2018 to September 2018 willing to give consent and meeting the inclusion criteria were included in the study after the clearance by ethical committee. A Mini-Mental State Exam (MMSE) score and $\mathrm{EtCO}_{2}$ levels (using a side-stream capnometer with $4 \mathrm{~L}$ of oxygen/minute) of operating surgeons were recorded just before the beginning and immediately after the completion of the surgery. The data were recorded, compared, and analyzed using SPSS software version 24. Surgeons were enquired for symptoms such as dizziness, confusion, headache, shortness of breath, and visual disturbances.

\section{Results}

The mean $\mathrm{EtCO}_{2}$ before surgery was found to be 30.86 with standard deviation of 4.03 and that after surgery was 31.23 with standard deviation of 3.85. Mean duration of laparoscopic surgeries was 73 minutes. Correlation of individual $\mathrm{EtCO}_{2}$ values before and after surgery did not show significant changes ( $p$ value $=0.534$ ). The difference in MMSE scale scores before and after surgery for all participated surgeons was insignificant. No effects were noted on decision-making, steadiness, and postural sway. The operating surgeons did not have any complaints in the postoperative period.

\section{Discussion}

Carbon dioxide $\left(\mathrm{CO}_{2}\right)$ is the product of cellular aerobic metabolism. It diffuses easily from cells into blood and erythrocytes and is transported to the lungs by venous blood through the function of cardiac output. Under normal conditions of circulation and ventilation, the partial pressure of $\mathrm{CO}_{2}$ approaches $50 \mathrm{~mm} \mathrm{Hg}$ at the level of tissues, and $45 \mathrm{~mm} \mathrm{Hg}$ in the venous blood. The difference between the latter and alveolar $\mathrm{CO}_{2}$ partial pressure $\left(\mathrm{PaCO}_{2}\right)$, which is around $40 \mathrm{~mm} \mathrm{Hg}$, is responsible for the diffusion of $\mathrm{CO}_{2}$ into the alveoli. There, $\mathrm{CO}_{2}$ is eliminated from the body with minute ventilation. Arterial $\mathrm{CO}_{2}$ partial pressure $\left(\mathrm{PaCO}_{2}\right)$ normally varies from 35 to $45 \mathrm{~mm} \mathrm{Hg}$. $^{10}$

Carbon dioxide is a colorless, odorless, and nonflammable gas, which because of its high safety profile is widely used to insufflate peritoneal cavities during laparoscopic surgeries. Being a highly soluble gas, it gets dissolved in blood soon after it is inhaled. It then binds to hemoglobin, and carboxyhemoglobin is formed, lowering hemoglobin's affinity for oxygen via Bohr's effect. ${ }^{11}$ Carbon dioxide does not only cause asphyxiation by hypoxia but also acts as a toxicant. At high concentrations (8\%), it has been shown to cause unconsciousness almost instantaneously and respiratory arrest within 1 minute. ${ }^{12}$

Thus, during laparoscopic surgeries following exposure to leaking carbon dioxide, $\mathrm{CO}_{2}$ can be readily absorbed into the bloodstream and may result in significant hypercarbia. 
In our study, we observed that there was no significant increase in the $\mathrm{EtCO}_{2}$ values before and after laparoscopic surgery in the surgeons. Considering the occupational safety and health administration guidelines, $\mathrm{CO}_{2}$ chromatography is advised for $\mathrm{CO}_{2}$ monitoring at workplaces, to prevent any untoward incidents. And when any such incident is confronted, necessary immediate and appropriate supportive care is provided.

In conclusion, our current study shows that despite being exposed to leaking $\mathrm{CO}_{2}$ during laparoscopic surgeries, the operating surgeons did not have significant changes in end-tidal carbon dioxide levels and the difference in MMSE scale scores was also insignificant. However, further studies involving a larger number of volunteers and prolonged duration of exposures need to be done with the specific monitoring of various blood parameters for a better understanding of the effects of $\mathrm{CO}_{2}$ exposure.

\section{References}

1. Naude GP, Bongard FS. Helium insufflation in laparoscopic surgery. Endosc Surg Allied Technol 1995;3(4):183-186. PMID: 8846034.

2. Fowler B, Elcombe DD, Kelso B, et al. The threshold for hypoxia effects on perceptual motor performance. Hum Factors 1987;29(1):61-66. DOI: 10.1177/001872088702900106.

3. Putz VR. The effects of carbon monoxide on dual-task performance. Hum Factors 1979;21(1):13-24. DOI: 10.1177/001872087902100103.
4. Roche S, Horvath S, Gliner J, et al. Sustained visual attention and carbon monoxide: elimination of adaptation effects. Hum Factors 1981;23(2):175-184. DOI: 10.1177/001872088102300205.

5. Weitzman DO, Kinner JS, Luria SM. Effects on vision of repeated measure to carbon dioxide (Technical Report No.6-8). New London, CT, USA:U.S. Navy Department, Bureau of Medicine and Surgery, Naval Submarine Medical Center, Submarine Medical Research Laboratory; 1969. p. 1-6.

6. Weybrew BB. An exploratory study of the psychological effects of intermittent exposure to elevated carbon dioxide levels (Technical Report No. 647). Groton, CT, USA: U.S. Navy Department, Bureau of Medicine and Surgery, Naval Submarine Medicine Center, Submarine Medical Research Laboratory; 1970. p. 1-9.

7. Brazier, Mary AB. The physiological effects of carbon dioxide on the activity of the CNS in man, Medicine: September 1943;22(3):205-222.

8. Mathison GC. The effects of asphyxia upon medullary centres: Part I. The vaso-motor centre. J Physiol 1911;42(4):283. DOI: 10.1113/ jphysiol.1911.sp001435.

9. https://www.osha.gov/dts/chemicalsampling/data/CH_225400.html.

10. Kupnik D, Skok P. capnometry in the prehospital setting: are we using its potential? Emerg Med J 2007;24(9):614-617. DOI: 10.1136/ emj.2006.044081.

11. Perrella M, Bresciani D, Rossi-Bernardi L. The binding of $\mathrm{CO}_{2}$ to human hemoglobin. J Biol Chem 1975;250(14):5413-5418. DOI: 10.1016/ S0021-9258(19)41197-6

12. Ikeda N, Takahashi $\mathrm{H}$, Umetsu K, et al. The course of respiration and circulation in death by carbon dioxide poisoning. Forensic Sci Int 1989;41(1-2):93-99. DOI: 10.1016/0379-0738(89)90240-5. 